\title{
"The impact of health informatics on public health emergency response during the COVID-19 pandemic in developing countries - systematic review"
}

Hewagama SP.

\begin{abstract}
Introduction: The world grapples with the unprecedented challenges of the Covid-19 pandemic with devastating economic and social impacts. The healthcare systems across developed and developing countries are laid a huge responsibility with immense pressure to combat this contemporary global crisis. With modern technological improvements health informatics (HI) plays a vital role in the public health emergency response (PHER). However, there is little empirical evidence to show the impact of $\mathrm{HI}$ in developing countries during this pandemic.
\end{abstract}

Objective: To determine how HI impacted the PHER during Covid-19 pandemic in developing countries.

Methodology: This study deployed a systemic review of published quality academic journals that emphasize and evaluate the HI role and impact during PHER in developing countries.

Results: The synthesized evidence in developed countries found that the technological advances in telemedicine, e-health and mobile devices have proven to possess huge potentials in controlling the pandemic spread with enormous rapid transformations of service delivery patterns, with high patient satisfaction. HI impact on developing countries reported a high positivity towards PHER during Covid-19 pandemic. The adoption rates were low in developing countries with the key determinants; digital technology, efficient health governance, partnership, collaboration in national \& international, infrastructure, stakeholder skills and acceptance.

The empirical research findings clearly showed the fundamental need to establish suitable HI initiative framework in developing countries in align with the countries national policies with medium to long-term plans and collaborative international partnerships. The level of maturity of HI needed to be deployed within health systems at pace and scale ready enough to save the world in most needed.

\section{Introduction}

\subsection{Background}

Today the world grapples with the challenges of the COVID-19 pandemic affecting more than 80 million worldwide, lading huge responsibilities towards the public health systems globally. Healthcare systems across developed and developing nations are being put under tremendous pressure with this novel coronavirus (Nagesh \& Chakraborty 2020). In particular, impact on developing countries at a higher rate, with imminent threats (CHP HKSARG 2020).

Health informatics (HI) is the application of information technology (IT) in the field of healthcare - clinical informatics, clinical research informatics, consumer $\mathrm{HI}$ (mobile devices, telemedicine), public HI (population \& community). Health informatics is mainly powered by various forms of information technologies, telecommunication infrastructures, systems and their practices (Mosa, Yoo and Sheets, 2012).

The arena of HI combined with healthcare data, and modern business concepts have gained an enormous improvement in healthcare industry (Kabakus et al, 2016). Several HI applications are used to fasten the surveillance processes with high accuracy in public health. Eg; WHO web-based surveillance network.

IT based tools can support institutions effectively in pandemic response by facilitating the faster widespread distribution of information with real time tracking, creating virtual platform for discussions and operations, offering telemedicine for distant. (Langabeer et al, 2016). The health informatics tools are essential to be leveraged to the full potential (Reeves et al, 2020).

The establishment of integrated healthcare system will also provide positive reference for designing future intelligent healthcare platforms. Though, there are some financial limitations in developing nations, this contemporary health crisis warrants effective implementation of HI. Therefore, it is of utmost important to come up with the findings on the HI impact on pandemic response in developing countries. 


\subsection{Aim \& objectives}

Aim of this research is to critically evaluate the impact of Health Informatics on the COVID-19 Pandemic response in developing countries.

\section{Objectives}

1. To assess the key determinants of HI use in PHER in developing countries.

2. To describe the key initiatives on HI in Covid-19 pandemic response in developing countries.

3. To critically evaluate how HI impact on the public health emergency response during Covid-19 in developed countries.

4. To establish suitable HI initiatives to enhance pandemic response in future pandemics in developing countries.

\section{Method of Analysis}

\subsection{Systematic review}

This research deploys a systemic review of credible quality academic journals aiming to evaluate the impact of health informatics on public health emergency response during Covid-19 response in developing countries. As per Saunders, Lewis and Thornhill (2012), systematic review is a process of reviewing the literature using pre-planned criteria in order to filter the most appropriate and current literature. The range of the articles was based upon the pre-determined principles laid around the scope of selected review. The articles published after 2010 were used in this review to identify the latest analyses on the topic. Hence, all the selected articles on the topic were shortlisted and filtered based on the relevance to the topic and importance. Finally, attempts to come for conclusions with evidence.
The key scope of this review is to get a reliable and objective overview of the currently available evidence on the research questions and to synthesize them. Thus, the main objective of this systematic review is to evaluate the impact of $\mathrm{HI}$ on Covid-19 pandemic response in developing countries. The evidence-based evaluation will be able to evaluate the core aim of the study with the filtered sources which is cited to support the reasoning. The entire process follows theory to data approach which is deductive (Saunders, Lewis and Thornhill, 2012), supported by Denscombe (2017), pointing out the use of deductive approach to underpin theory to data. Furthermore, he stated the importance of using quantitative data while conducting a qualitative research.

\subsection{Search criteria}

For this systematic review, studies were selected from Emerald insight, Elsevier, Pubmed, Scimago, Google scholar research databases focusing the areas of public health emergency response, health informatics, key determinants of HI in Covid-19 PHER in developing \& developed countries including recent research relevant to HI and PHER in developing countries and related themes.

\subsection{Inclusion \& exclusion process}

The peer-reviewed quality academic journals published after 2010 were considered by the author to evaluate the findings related to the research topic. Several key words were used to find most relevant articles.

The filtering was done as per the PRISMA model. Relevant and important academic journal articles were filtered considering priority, duplication, elimination to extract the most appropriate which can find out the answers and accomplishing the aim and objectives of the research. 
Figure 5: Flow diagram of research selection as per PRISMA checklist

\section{PRISMA Diagram}
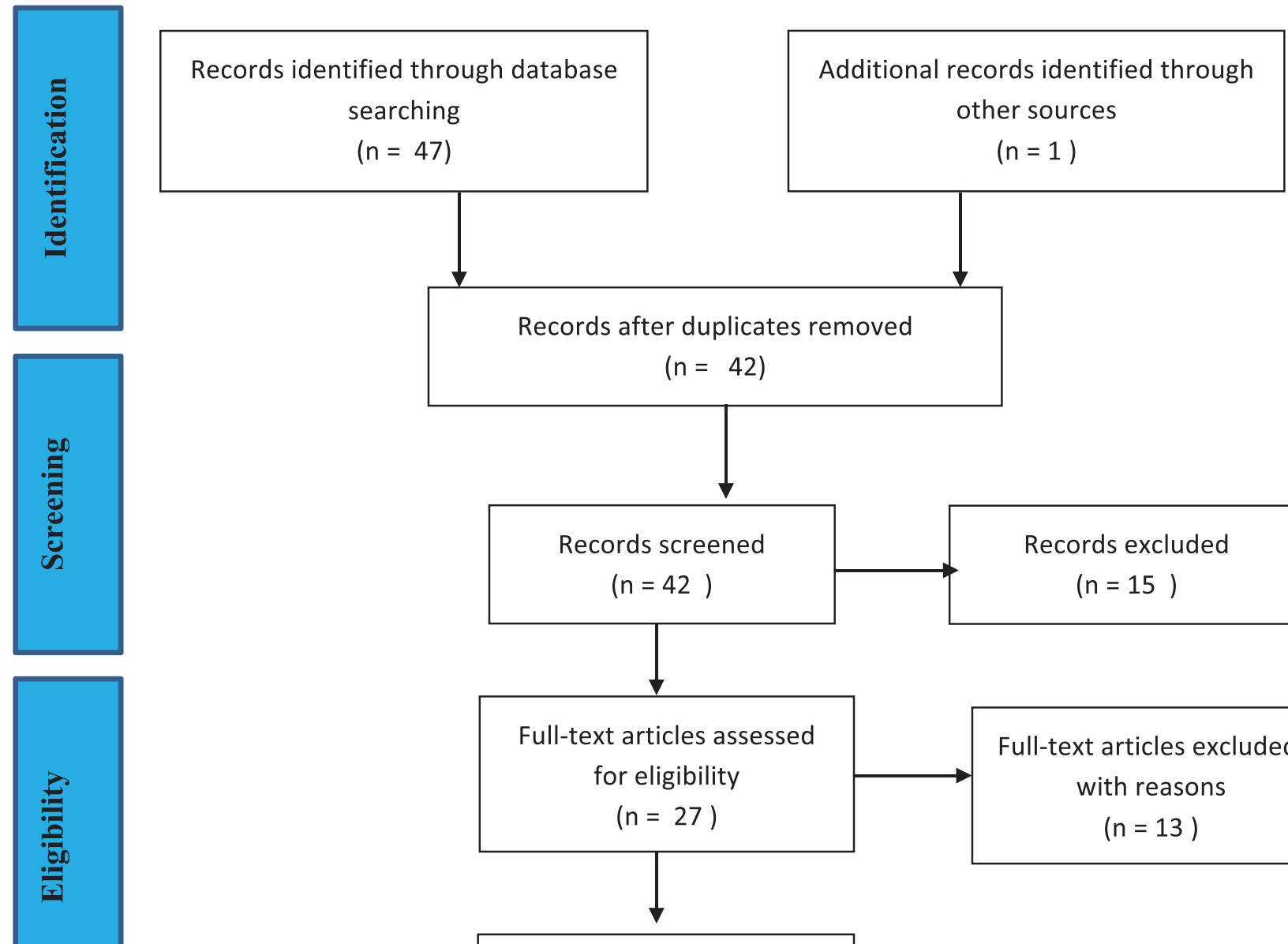

Records excluded

$(n=15)$

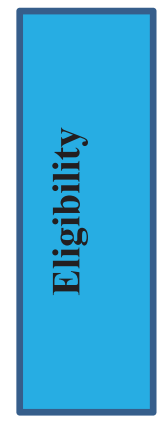

Studies included in

qualitative synthesis

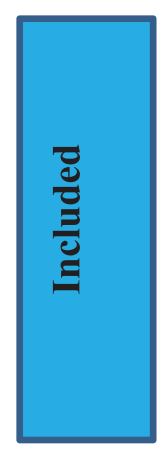

$$
(n=11)
$$

Full-text articles excluded, with reasons

$(n=13)$

\subsection{Thematic analysis}

As per Saunders, et al., (2016) thematic analysis is one of the major tools and foundational method that support the analysis of qualitative data. Thus, it assists researchers on breaking down the qualitative data into thematic manner in order to create the codes. These coding methods finally identify the themes. Under this guidance the author used codifications and the qualitative data was tabulated as per the themes. Initial themes identified from literature review are structured under three key themes.
1. Key determinants of HI \& health sector response in developing countries

2. The role \& key initiative of $\mathrm{HI}$ in the public health emergency response in developed countries

3. Initiatives to enhance the future pandemic response in developing countries 


\section{Conclusions \& Recommendations}

This systematic review was aimed to critically analyze the best available data on the impact of Health Informatics (HI) on the COVID-19 pandemic response in developing countries and subsequently to establish an appropriate framework with suitable $\mathrm{HI}$ initiatives for developing countries. Fundamental need to establish suitable HI initiative in the developing nations was that, the systematic review revealed the high positivity related to HI use in PHER with the Covid-19 pandemic experience.

With that motivation it is then set to process of establishing most suitable initiative framework for developing countries incorporating the related key factors and performance measures. The key determinants were identified fulfilling the first objective by synthesizing all the articles. It should be appreciated that the key determining factors are common to both developed and developing regions except the factor of funding which is critical for the developing countries.

The light of the researchers revealed low adoption rates in developing countries compared to the developed world and the key determinants; the digital technology, efficient health governance, and civil partnership. Further, ICT infrastructure, internet penetration, user perceptions, collaboration specially the national \& international were also identified as influencing factors. Finally, synthesizing the evidence of systematic review on key determinants it could be summarized as the infrastructure, stakeholder skills and acceptance.

Telemedicine and mobile devices were identified in most studies as initiatives in developing countries in combating Covid-19 with live video conferencing, wireless remote monitoring, distant multi-disciplinary care, health education, collecting health information, transforming and evaluation. As the COVID-19 pandemic scales exponentially across the countries, calls for extended use of telehealth and other innovative solutions, validates the concept of having well integrated virtual health platforms for developing countries with enormous rapid transformations of service delivery patterns. In addition, several prediction models were developed for diagnosis and prognosis of covid-19 globally.
The synthesized evidence in developed countries found that the technological advances in telemedicine have proven to possess huge potentials in controlling the pandemic spread with enormous rapid transformations of service delivery patterns. The experience suggested the level of maturity needed to be deployed within health systems at pace and scale addressing the fact that the available HI technologies are not ready enough to save the world in most needed. Also the evidence reported high patient satisfaction with HI practices in developed countries. French telemedicine system provides an example for a well-established HI system.

Overall, the evidence depicts the possible roles of health informatics played in moving forward the technology that supports healthcare both in developed and developing countries. The experience from developed countries during Covid-19 pandemic response can guide the way of developing world to combat public health emergencies. The emerging technologies like telemedicine, and artificial intelligence, cloud computing, 4G mobile communications are becoming indispensible in emergency response.

As user engagement revealed as a vital factor it is important to improve the skills among stakeholders. Finally, it is essential to have stringent measures in developing countries to ensure the data security and integrity. Also the prediction models carry a high risk of bias and are still at primary stages. It is vital to have national and international partnerships for successful future health IT solutions in developing countries. Drawing on experience and the lessons learned from developed world, and considering progress in technology during this contemporary crisis, it is imperative to incorporate suitable HI initiatives for PHER in the healthcare systems of developing countries. With the most available knowledge derived from the review, the author proposes a framework exploiting new avenues for future research.

As depicted in the figure the author proposes a framework. 
Figure 1: Framework for developing countries HI initiatives.
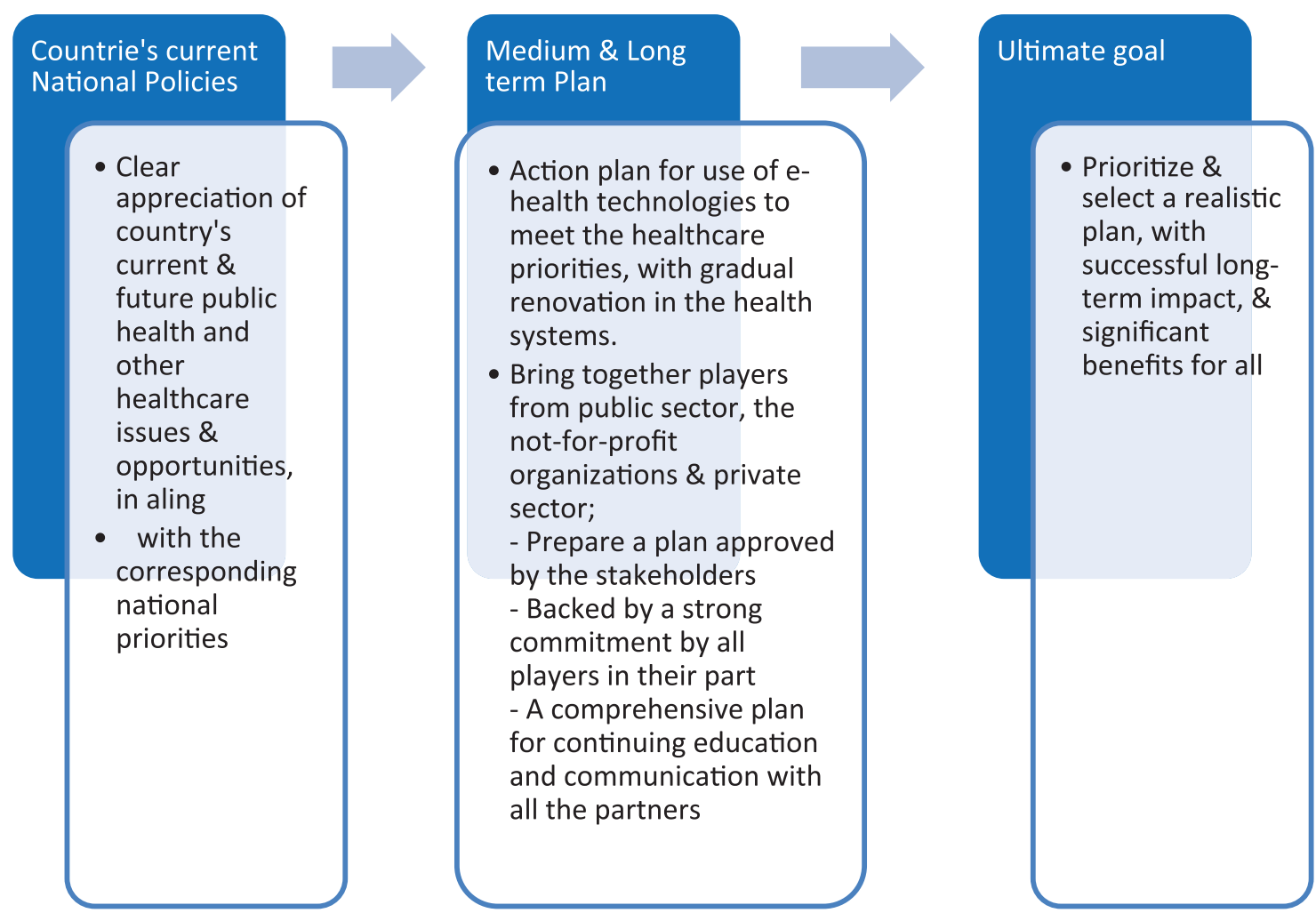

Findings from this study depict e-health and telemedicine's transformative impact on PHER and the rapid shift in the virtual platform adoption in healthcare. Although, HI cannot completely solve the issues caused by COVID-19 in health, it can help to flatten infection curve of COVID-19. The implications of this research will guide the way of future researches on suitable, effective and sustainable HI initiatives for developing countries to combat more efficiently.

Since this study is a systematic review, it carries some own limitations. Some limitations occurred for this study due to issues in language, accessibility and skipped attention. The factors discussed in this paper essential to be generalized with caution and can be varied within different countries. Therefore the proposed framework by the author needed to be validated through further survey or case study by using primary data and mixed method.

\section{References}

1. Aziz, H. (2017) 'A review of the role of public health informatics in healthcare', Journal of Taibah University Medical Sciences, 12(1), pp.78-81.

2. Bakken, S. (2020) 'Informatics is a critical strategy in combating the COVID-19 pandemic', Journal of the American Medical Informatics Association, 27(6), pp.843-844.
3. Bokolo, A. (2020) 'Use of Telemedicine and Virtual Care for Remote Treatment in Response to COVID-19 Pandemic,' J Med Syst, 44, pp.132, https://doi.org/10.1007/s10916-020-01596-5

4. Bokolo, A. (2020) 'Exploring the adoption of telemedicine and virtual software for care of outpatients during and after COVID-19 pandemic,' Ir J Med Sci (2020). https://doi.org/10.1007/ s11845-020-02299-z

5. Briner, R., Walshe, N. (2015) 'From Passively Received Wisdom to Actively Constructed Knowledge': Teaching Systematic Review Skills As a Foundation of Evidence-Based Management. Academy of Management Learning (1): 63-80.

6. Budd, J. et al. (2020) 'Digital technologies in the public-health response to COVID-19'. Nat Med 26, 1183-1192 (2020). https://doi.org/10.1038/s41591020-1011-4

7. Chp.gov.hk. (2020). 'Countries/areas with reported cases of Coronavirus Disease-2019 (COVID19)'Centre for Health Protection. [online] Available at: https://www.chp.gov.hk.

8. Davis, F. (1989). 'Perceived Usefulness, Perceived Ease of Use, and User Acceptance of Information Technology'. MIS Quarterly, 13(3), 319-340. doi:10.2307/249008 
9. Denscombe, M. (2017) 'The good research guide: for small-scale social research projects'. 6th ed. London: Open University Press. http://hdl.handle. net/2086/14885

10. Doshi, A., Dressen, J. (2020) 'Keep calm and $\log$ on: telemedicine for COVID-19 pandemic response', SFHM JCS, 15(5), pp.302-304.

11. Evans, O. (2020) 'Socio-economic impacts of novel coronavirus: The policy solution', Bizecons Quarterly,7,pp.3-12.

12. Garavand, A. et al. (2016) 'Factors influencing the adoption of health information technologies: a systematic review'. Electron Physician, 8(08), pp.2713-2718.

13. Gostin, L., Lucey, D., Phelan A. (2014) 'The Ebola Epidemic: A Global Health Emergency’, JAMA, 312(11), pp.1095-1096.

14. Hameed, M., Counsell, S., Swift, S. (2012) 'A conceptual model for the process of IT innovation adoption in organizations', J. Eng. Technol. Manage, vol.29, (3), pp.358-390.

15. Holden, R., Karsh, B. (2010) 'The technology acceptance model: its past and its future in health care', J Biomed Inform, 43(01), pp.159-172.

16. Hu, P., et al. (1999) 'Examining the technology acceptance model using physician acceptance of telemedicine technology', Journal of management information systems, 16(2), pp.91-112.

17. Joshi, A., et al. (2020) 'Impact of emergency department tele-intake on left without being seen and throughput metrics', Acad Emerg Med, 27(2), pp.139-47.13.

18. Kabakus, et al. (2016) 'The Importance of Informatics for Health Care Industry', Acta Medica Anatolia, 4, pp.124-125.

19. Keesara, S., Jonas, A., Schulman, K. (2020) 'Covid-19 and health care's digital revolution', N Engl J Med, 382, e8.

20. Kim, J., Park, H. (2012) 'Development of a health information technology acceptance model using consumers' health behavior intention,' Journal of medical Internet research; 14(5):e133.

21. Krusina, A., et al. (2020) 'Developing a Data Integrated COVID-19 Tracking System for
Decision-Making and Public Use,' International Journal of Population Data Science, 5(4).

22. Kuperman, G. (2011) 'Health-information exchange: why are we doing it, and what are we doing,' J Am Med Inform Assoc, 18(5), pp.678682 .

23. Langabeer J., et al. (2016) 'Telehealth-enabled emergency medical services program reduces ambulance transport to urban emergency departments,' West J Emerg Med 2016;17(6), pp.713-720. doi: 10.5811/westjem.2016.8.30660.

24. Lee,Y.,Hsieh, Y.,Hsu,C.(2011) 'Adding innovation diffusion theory to the technology acceptance model: Supporting employees' intentions to use e-learning systems', J. Educ. Technol. Soc,14(4), pp. 124-137.

25. Lee, D., Heo, K. and Seo, Y. (2020). 'COVID-19 in South Korea: Lessons for developing countries.' World Development, 135, p.105057. https://doi. org/10.1016/j.worlddev.2020.105057

26. Luna, D., Almerares, A., Mayan, J.C., González Bernaldo de Quirós, F. and Otero, C. (2014). 'Health Informatics in Developing Countries: Going beyond Pilot Practices to Sustainable Implementations': A Review of the Current Challenges. Healthcare Informatics Research, [online] 20(1), p.3. Available at: https://www.ncbi.nlm.nih.gov/pmc/articles/ PMC3950262/.

27. Mahmood, S., Hasan, K., Colder, M., Labrique, A. (2020) 'Global Preparedness Against COVID-19: We Must Leverage the Power of Digital Health,' JMIR Public Health Surveill 6(2), e18980, URL: https://publichealth.jmir.org/2020/2/e18980, DOI: $10.2196 / 18980$

28. Mann, D.M., Chen, J., Chunara, R., Testa, P.A. and Nov, O. (2020). 'COVID-19 transforms health care through telemedicine: evidence from the field.' Journal of the American Medical Informatics Association, 27(7). doi: 10.1093/jamia/ocaa072.

29. Moher D., et al. (2015) 'Preferred Reporting Items for Systematic Review and Meta-Analysis Protocols (PRISMA-P) 2015 statement'. Syst Rev. 2015;4(1):1.

30. Monaghesh, E., Hajizadeh, A. (2020) 'The role of telehealth during COVID-19 outbreak: a systematic review based on current evidence,' BMC Public Health 20,1193. https://doi.org/10.1186/s12889020-09301-4. 
31. Mugo, David M., Nzuki. (2014) 'Determinants of electronic health in developing countries', International Journal of Arts and Commerce 3(3), 49-60.

32. Nadri et al. (2018) 'Factors affecting acceptance of hospital information systems based on extended technology acceptance model: a case study in three paraclinical departments,' Appl Clin Inform. 2018;9(02):238-247.

33. Ohannessian, R., Duong, T., \& Odone, A. (2020) 'Global Telemedicine Implementation and Integration Within Health Systems to Fight the COVID-19 Pandemic; A Call to Action,' JMIR public health and surveillance, 6(2), e18810. https:// doi.org/10.2196/18810.

34. Panir, M.J.H. (2011). 'Role of ICTs in the Health Sector in Developing Countries: A Critical Review of Literature'. Journal of Health Informatics in Developing Countries, [online] 5(1). Available at: https://www.jhidc.org/index.php/jhidc/article/ view/61 [Accessed 14 Dec. 2021].

35. Peeri N.,et al. (2020) 'The SARS, MERS and novel coronavirus (COVID-19) epidemics, the newest and biggest global health threats': what lessons have we learned? Int J Epidemiol.

36. Peek, N., Sujan, M., Scott, P. (2020) 'Digital health and care in pandemic times: impact of COVID-19,' BMJ Health Care Inform, 27(1),e100166. doi: 10.1136/bmjhci-2020-100166.

37. Kummitha R. (2020) 'Smart technologies for fighting pandemics: The techno- and human- driven approaches in controlling the virus transmission.' Government information quarterly, 37(3), 101481. https://doi.org/10.1016/j.giq.2020.101481

38. Ramaswamy, A., et al. (2020) 'Patient Satisfaction With Telemedicine During the COVID-19 Pandemic: Retrospective Cohort Study,' J Med Internet Res, 22(9), e2078

39. Reeves, J et al., (2020) 'Rapid Response to COVID-19: Health Informatics Support for Outbreak Management in an Academic Health System,' Journal of the American Medical Informatics Association, Volume 27(6), pp. 853859.

40. Robert A., Airo H. (2020) 'COVID-19, digital privacy, and the social limits on data-focused public health responses,' International Journal of Information Management, 55.

41. Saunders, M., Lewis, P., Thornhill, A., (2019) 'Research methods for business students.' 8th Edn. Pearson Education Limited, Haerlow, England.

42. Stanberry, B. (1998) 'The legal and ethical aspects of telemedicine. : Data protection, security and European law,' J. Telemed. Telecare, 4,pp.18-24.

43. Surendran P. (2013) 'Technology acceptance model: a survey of literature,' Int J Business Soc Res.2(04),pp.4.

44. Tobbin, P. (2010) 'Modeling adoption of mobile money transfer: A consumer behaviour analysi', Proc. 2nd Int. Conf. Mobile Commun. Technol. Develop., 2010.

45. Whaibeh, E., Mahmoud, H., Naal, H. (2020) 'Telemental health in the context of a pandemic: the COVID-19 experience,' Curr Treat Options Psychiatry, 7, pp.198-202.

46. Ward, R. (2013) 'The application of technology acceptance and diffusion of innovation models in healthcare informatics,' Health Policy and Technology, 2(4), pp.222-228.

47. Weigel et al., (2014) 'Diffusion of Innovations: A Foundational Theory for Medical Informatics Research.' 10.4018/978-1-4666-4619-3.ch008.

48. Wynants, et al. (2020) 'Prediction models for diagnosis and prognosis of covid-19: systematic review and critical appraisal,' BMJ, 369, pp.1328.

49. Ye, J. (2020) 'The Role of Health Technology and Informatics in a Global Public Health Emergency: Practices and Implications From the COVID-19 Pandemic,' JMIR Med Inform,8(7).

50. Ye, Q., Zhou, J., \& Wu, H. (2020) 'Using Information Technology to Manage the COVID-19 Pandemic: Development of a Technical Framework Based on Practical Experience in Chin,' JMIR medical informatics, 8(6).

51. Zhai, Y., Wang, Y., Zhang, M., Gittell, J.H., Jiang, S., Chen, B., Cui, F., He, X., Zhao, J. and Wang, X. (2020). 'From Isolation to Coordination: How Can Telemedicine Help Combat the COVID-19 Outbreak?' 10.1101/2020.02.20.20025957. 